\title{
PENGARUH WORK - LIFE BALANCE, KEPUASAN KERJA DAN WORK ENGAGEMENT TERHADAP TURNOVER INTENTIONS DENGAN MENTORING SEBAGAI VARIABEL MODERATING PADA KARYAWAN HOTEL DAFAM SEMARANG
}

\author{
Bernardus Ferry Wahyu Laksono ${ }^{1)}$; Paulus Wardoyo ${ }^{2)}$ \\ bernardusferry@gmail.com ${ }^{1)}$; paulus_w@usm.ac.id ${ }^{2}$
}

Magister Manajemen, Universitas Semarang, Semarang, Indonesia

\begin{tabular}{l} 
Info Artikel \\
\hline Sejarah Artikel: \\
Diterima ;03-12-2018 \\
Disetujui ;03-01-2019 \\
Dipublikasikan ;07-04- \\
2019 \\
\hline Keywords: \\
Work- Life Balance; \\
Kepuasan Kerja; Work \\
Engagement; Mentoring; \\
Turnover Intentions; \\
smart-PLS
\end{tabular}

\begin{abstract}
Abstrak
Turnover intentions merupakan hal yang dihindari dari suatu organisasi, karena fenomena turnover memiliki biaya yang signifikan dan konsekuensi negatif lainnya untuk setiap organisasi. Penelitian ini ingin mengetahui pengaruh work - life balance, kepuasan kerja, work engagement terhadap turnover intentions, dan juga pengaruh work life balance, kepuasan kerja, work engagement yang dimoderasi oleh mentoring terhadap turnover intentions.

Metode penelitian yang digunakan adalah menggunakan pendekatan kuantitatif. Metode pengumpulan data dalam penelitian ini adalah metode kuesioner, dan skala pengumpulan data dengan skala likert. Data yang ada kemudian dianalisa menggunakan aplikasi smart-PLS versi 3.2.7.

Terdapat pengaruh negatif signifikan dari setiap variabel bebasnya. Hal ini menunjukkan bahwa setiap variabel baik Work - Life Balance, Kepuasan Kerja, Work Engagement, dan Mentoring telah berkontribusi menekan tingginya Turnover Intentions di Hotel Dafam Semarang.
\end{abstract}

\section{EFFECT OF WORK - LIFE BALANCE, WORK SATISFACTION AND WORK ENGAGEMENT ON TURNOVER INTENTIONS WITH MENTORING AS MODERATING VARIABLES IN EMPLOYEE DAFAM HOTEL SEMARANG}

\begin{abstract}
Turnover intentions are avoided by an organization, because the turnover phenomenon has significant costs and other negative consequences for each organization. This study wanted to know the effect of work-life balance, job satisfaction, work engagement on turnover intentions, and also the effect of work-life balance, job satisfaction, work engagement which was moderated by mentoring towards turnover intentions.

The research method used is to use a quantitative approach. The method of data collection in this study is the questionnaire method, and the scale of data collection with the Likert scale. The data is then analyzed using the smart-PLS version 3.2. 7 application.

There is a significant negative effect of each independent variable. This shows that each variable both Work - Life Balance, Job Satisfaction, Work Engagement, and Mentoring have contributed to suppressing the high turnover intensity at Dafam Hotel Semarang.
\end{abstract}

\footnotetext{
Alamat korespondensi :

Magister Manajemen, Universitas Semarang, Jl. Soekarno Hatta, Semarang

ISSN

E-mail: bernardusferry@gmail.com

1979-480o (cetak) 2580-8451 (online)
} 


\section{PENDAHULUAN}

Turnover intentions didefinisikan sebagai "kemauan sadar dan disengaja untuk meninggalkan organisasi" (Tett \& Meyer 1993: 262). Dengan kata lain, sejauh mana seorang karyawan berencana untuk pergi atau tinggal bersama organisasi (Bothma \& Roodt 2013; Jacobs \& Roodt 2011). Menurut Tett dan Meyer (1993), niat untuk meninggalkan organisasi adalah langkah terakhir dalam serangkaian penarikan kognisi yang mengarah ke perputaran yang sebenarnya. Kepuasan kerja dan Turnover intentions ditemukan sebagai prekursor dalam proses penarikan yang memprediksi pergantian karyawan secara sukarela (Du Plooy \& Roodt 2010). (Oosthuizen, Coetzee, \& Munro, 2016) Bothma (2011) menyimpulkan bahwa fenomena turnover memiliki biaya yang signifikan dan konsekuensi negatif lainnya untuk setiap organisasi (Bluedorn, 1982; Greyling \& Stanz, 2010; Mobley, 1982). Kehilangan karyawan yang sangat terampil mungkin memiliki implikasi mengganggu untuk organisasi, seperti gangguan fungsi organisasi, penyampaian layanan dan administrasi. Ini juga dapat berkontribusi pada peningkatan biaya rekruitmen karyawan baru dan training karyawan baru (Roodt \& Bothma, 1997; Sulu, Ceylan \& Kaynak, 2010).

Penelitian Weyland pada tahun 2011, menunjukkan bahwa penyebab turnover intentions karyawan Generasi Y tinggi adalah apabila perusahaan menerapkan jam kerja yang ketat dan tidak fleksibel. Hal ini dikarenakan Generasi Y mengutamakan work life balance atau keseimbangan antara kehidupan pribadi dan kehidupan kerja. Penelitian Olawale dan Olarewaju (2016) menyimpulkan bahwa ada hubungan yang signifikan antara kepuasan kerja karyawan dengan turnover intentions karyawan. Menurut Saks (2006), keterlibatan kerja dapat dikonseptualisasikan sebagai antecedent atau yang mendahului dari turnover intentions.

Dari 83 karyawan Hotel Dafam Semarang, dimana 71 karyawn merupakan Generasi Y dan 12 karyawan sisanya merupakan karyawan Generasi X, dalam setahun terakhir ada 9 karyawan yang resign atau terjadi turnover, hal tersebut menandakan turnover rate sekitar 11\% dalam satu tahun. Menurut Flippo (1994), turnover karyawan dalam sebuah perusahaan masih dianggap wajar dan normal dalam kurun waktu tertentu yaitu sebesar 3\%. Sedangkan menurut Supriyanto (2003) umumnya dinyatakan dalam satu tahun, turnover tidak boleh lebih dari $10 \%$ pertahun.

Berdasarkan latar belakang tersebut, maka diperoleh adanya turnover intentions yang tinggi pada Karyawan Hotel Dafam Semarang, selain itu adanya kontroversi dari penelitian tentang pengaruh Work - Life Balance terhadap turnover intentions pada Generasi Y. Oleh karena itu perumusan masalahnya adalah penulis ingin mengetahui lebih jauh pengaruh dari work - life balance terhadap turnover intentions, dengan memasukkan mentoring sebagai variabel moderating.

Tujuan dari penelitian tesis ini sesuai dengan perumusan masalah di atas adalah untuk menganalisis pengaruh work - life balance terhadap turnover intentions; menganalisis pengaruh kepuasan kerja terhadap turnover intentions; menganalisis pengaruh work engagement terhadap turnover intentions; menganalisis pengaruh work life balance yang dimoderasi oleh mentoring terhadap turnover intentions; menganalisis pengaruh kepuasan kerja yang dimoderasi oleh mentoring terhadap turnover intentions; menganalisis pengaruh work engagement yang dimoderasi oleh mentoring terhadap turnover intentions. 


\section{TELAAH PUSTAKA}

\section{Turnover Intentions}

Turnover telah menjadi perhatian utama bagi manajemen di abad ini karena organisasi melakukan investasi besar pada karyawan mereka dalam hal merekrut, melatih, mengembangkan dan mempertahankan mereka. Turnover intentions dapat didefinisikan sebagai niat seorang karyawan untuk berhenti dari pekerjaannya saat ini dan membuang keanggotaan organisasinya (Meyer \& Allen, 1984). Perputaran juga dapat disebut sebagai transfer karyawan di seluruh batas organisasi (Macy \& Mirvis, 1976). Berbagai studi menganggap turnover intentions sebagai anteseden utama dari turnover (Bluedorn 1982; Mobley WH, Horner, \& Hollingsworth 1978; Mobley, Griffith, Tangan, \& Megline, 1979; Steel \& Ovalle, 1984). Perputaran dapat bersifat sukarela maupun tidak sukarela. (Hassan, Akram, \& Naz, 2012)

Niat untuk berhenti didefinisikan sebagai keinginan, upaya, atau keinginan untuk meninggalkan tempat kerja saat ini secara sukarela. Ini lebih lanjut didefinisikan sebagai niat seorang karyawan untuk mengakhiri keanggotaan organisasinya (Hassan, Akram, \& Naz, 2012). Niat untuk berhenti ditemukan menjadi indikator kuat dari perilaku berhenti yang sebenarnya, karena beberapa penelitian menemukan korelasi rata-rata tertimbang yang kuat antara niat untuk berhenti dan berhenti yang sebenarnya (Firth et al., 2004).

\section{Work - Life Balance}

Work - life balance didefinisikan sebagai tingkat di mana seorang individu terlibat dan sama-sama puas dengan peran pekerjaannya dan peran keluarga yang terdiri dari tiga dimensi keseimbangan kerja - keluarga, yaitu: keseimbangan waktu, keseimbangan keterlibatan dan keseimbangan kepuasan (Greenhaus, Collins \& Shaw 2003). Sisa waktu melibatkan mencurahkan waktu yang sama untuk bekerja dan keluarga. Keseimbangan melibatkan melibatkan keterlibatan yang sama dalam pekerjaan dan keluarga (Greenhaus et al. 2003). Kepuasan keseimbangan berarti kepuasan yang setara dengan pekerjaan dan keluarga (Greenhaus dkk. 2003; Chimote \& Srivastava 2013).

Work - life balance didefinisikan sebagai jumlah waktu yang dihabiskan untuk melakukan pekerjaan, dibandingkan dengan jumlah waktu yang dihabiskan bersama keluarga dan melakukan hal-hal yang kita nikmati. Jadwal yang tidak dapat diatur dan kehidupan di rumah yang tidak terkontrol dapat menyebabkan depresi, kinerja buruk di tempat kerja, dan konflik dengan keluarga dan perasaan kelelahan. Work - life balance adalah keadaan keseimbangan yang nyaman dicapai antara prioritas utama karyawan dari posisi pekerjaan mereka dan gaya hidup pribadi mereka. Sebagian besar psikolog akan setuju bahwa tuntutan karier karyawan tidak boleh membebani kemampuan individu untuk menikmati kehidupan pribadi yang memuaskan di luar lingkungan kerja. (Alvesteffer, 2016)

Work - life balance sangat penting untuk keterlibatan Generasi Y atau Millennials. Memiliki waktu luang yang cukup merupakan sumber penting kesejahteraan di tempat kerja (Kultalahti et al., 2014). Supervisor memainkan peran besar dalam keterlibatan Generasi Y atau Millennials. Supervisor yang melakukan jenis otoritas yang salah, supervisor yang tidak memberikan umpan balik atau hanya memberikan umpan balik negatif yang menyebabkan Generasi Y tidak mau terlibat, dimana akan meningkatkan turnover intentions. Pada saat yang sama, mereka perlu diperlakukan dengan baik dan dihormati sebagai individu manusia daripada hanya 
karyawan. (Liyanage \& Gamage, 2017)

\section{Kepuasan Kerja}

Istilah "kepuasan" merujuk pada sikap umum seseorang individu terhadap pekerjaanya. Seseorang dengan tingkat kepuasan kerja tinggi menunjukkan sikap yang positif terhadap kerja. Kepuasan kerja menjadi masalah yang cukup menarik dan penting, karena sangat besar manfaatnya baik untuk kepentingan individu, industri, dan masyarakat. Kepentingan individu, penelitian tentang sebab-sebab dan sumber-sumber kepuasan kerja memungkinkan timbulnya usaha-usaha peningkatan kebahagiaan hidup mereka. industri, penelitian menganai kepuasan kerja dilakukan dalam rangka usaha peningkatan produksi dan pengurangan biaya melalui perbaikan sikap dan tingkah laku karyawannya. Selanjutnya, kepentingan masyarakat tentu akan menikmati hasil kapasitas maksimum dari industry serta naiknya nilai manusia di dalam konteks pekerjaan. (Sutrisno, 2017)

Untuk dapat melakukannya dengan tepat dan "kena sasaran", diperlukan pemahaman tentang teknik dan cara yang dapat digunakan untuk mengukur tingkat kepuasan para karyawan tersebut. Dalam hubungan ini perlu diperhatikan bahwa pekerja tidak melakukan tugasnya dalam suasana kehampaan. Artinya, seseorang dalam pelaksanaan tugas yang dipercayakan kepadanya tidak membatasi keberadaanya dalam organisasi hanya pada penyelesaian tugas itu berdasarkan ketrampilan dan deskripsi tugas yang mungkin sangat jelas. Akan tetapi tidak boleh dilupakan bahwa di samping hal-hal yang bersifat teknis tersebut, terdapat faktor-faktor lain yang sifatnya tidak teknis, melainkan psikologis, sosio-kultural dan intelektual. (Siagian, 2012)

\section{Work Engagement}

Menurut Lockwood (2007), work engagement diakui sebagai inisiatif bisnis yang terkait dengan keberhasilan organisasi. Work engagement didefinisikan sebagai 'keadaan pikiran yang positif, memuaskan, berhubungan dengan pekerjaan, paling sering ditandai oleh kekuatan, dedikasi dan penyerapan' (Schaufeli, Salanova, González- Romá \& Bakker, 2002). Dalam hal ini, konsep kekuatan, dedikasi dan penyerapan merupakan tiga komponen yang berbeda dari keterlibatan kerja, yaitu fisik, emosional dan kognitif. (Geldenhuys, Łaba, \& Venter, 2014)

Work engagement adalah konsep teoritis yang telah muncul di bidang psikologi (Bakker et al., 2008) dan penelitian dalam work engagement telah menjadi fokus perhatian selama sepuluh tahun terakhir, yang berpuncak pada dua aliran pemikiran berbeda yang membedakan kelelahan dari keterlibatan kerja (Maslach, Schaufeli \& Leiter, 2001; Schaufeli, Salanova, Gonzalez- Roma \& Bakker, 2002). Menurut Schaufeli et al. (2002), work engagement adalah keadaan kognitif konstan dan afektif yang tidak berfokus pada objek, kejadian atau perilaku individu. Sebagaimana ditunjukkan dalam definisi, keterlibatan memiliki tiga komponen utama. Yang pertama adalah semangat, yang berhubungan dengan peningkatan tingkat energi dan ketahanan mental ketika sibuk dengan aktivitas kerja, kesediaan untuk menginvestasikan upaya dalam aktivitas kerja seseorang dan menunjukkan ketekunan ketika menghadapi kesulitan. Dengan demikian, karyawan yang merasa bersemangat di tempat kerja sangat termotivasi oleh pekerjaan mereka dan cenderung tetap gigih ketika menghadapi kesulitan (Mauno, Kinnunen \& Ruokolainen, 2006). Komponen kedua, dedikasi, ditandai oleh keterlibatan dan kebanggaan yang kuat dalam pekerjaan seseorang, ditambah dengan rasa signifikansi, gairah, dan inspirasi. Dimensi akhir dari keterlibatan 
kerja adalah penyerapan, yang dicirikan sebagai sangat terfokus dan terserap dalam pekerjaan seseorang yang melewati dengan cepat dan seseorang memiliki kesulitan untuk melepaskan diri dari aktivitas kerja (Schaufeli et al., 2002). (Takawira et al., 2014)

\section{Mentoring}

Mentoring telah lama disajikan dalam literatur manajemen sebagai program pengembangan sumber daya manusia (Ghosh, R., 2012) atau sumber belajar pribadi (Lankau, M.J. \& Scandura, T.A., 2002). Sulit untuk membedakan mentoring dari istilah yang serupa, seperti memberi nasihat, konseling, dan mengajar. Selain hubungan perkembangan antara mentor yang lebih berpengalaman dan anak didik yang kurang berpengalaman, karakteristik unik dari mentoring adalah untuk mendiskusikan pemikiran anak didik mengenai perkembangan masa depan (Bozeman, B. \& Feeney, M.K., 2008). (Woo, 2017)

Mentoring di tempat kerja semakin penting dan menarik perhatian setiap tahunnya. Hal ini terutama karena pendampingan dalam kehidupan bisnis membawa sejumlah manfaat bagi organisasi selama beberapa tahun (Levinson, Darrow, Klein, Levinson dan McKee, 1978; Roche, 1979). Misalnya kepuasan kerja, promosi dan pembayaran gaji yang lebih tinggi dapat didaftarkan sebagai manfaat signifikan mentoring (Whitely, Dougherty dan Dreher, 1991; Dreher dan Ash, 1990; Fagenson, 1989; Turban dan Dougherty, 1994; Chao, Walz dan Gardner, 1992 ; Whitely dan Coetsier, 1993). (Çetin, Kızıl, \& Zengin, 2013) Mentoring memberikan hasil positif untuk anak didik dalam bentuk peningkatan kepuasan karyawan, kejelasan peran, selfefficacy, pembelajaran pribadi, pengembangan profesi dan kepuasan karir (Eastman dan Williams, 1993; Murphy dan Ensher, 2001; Young dan Perrewe, 2000) (Jyoti \& Sharma, 2015)

\section{Hubungan antara Work - Life Balance dengan Turnover Intentions}

Penelitian yang dilakukan oleh Malik et al., (2010) menunjukkan bahwa kehidupan kerja-keluarga yang tidak seimbang yang disebabkan oleh tuntutan kerja yang meningkat mengarah ke tingkat stres yang lebih tinggi. Kebijakan Work - Life Balance telah ditemukan untuk mengurangi ketidakhadiran dan berdampak positif terhadap produktivitas, dan turnover intentions karyawan. Grady et al., (2008) menekankan pentingnya bagi organisasi untuk mengimplementasikan inisiatif Work Life Balance. Organisasi yang memberikan manfaat seperti itu tampaknya memahami hubungan antara Work - Life Balance yang lebih besar dan retensi tenaga kerja yang kompeten, dan pengaruhnya terhadap komitmen organisasi dan profitabilitas. (Chemirmir, Musebe, \& Nassiuma, 2018)

Work - life balance yang rendah juga dapat menyebabkan karyawan mengalami moralitas rendah dan ketidakhadiran yang lebih tinggi dan organisasi mengalami turnover staf yang lebih tinggi, produktivitas yang lebih rendah dan kualitas kerja yang lebih rendah (Seligman, 2011). Manfaat dari program work - life balance untuk karyawan termasuk peningkatan kontrol karyawan dari waktu ke waktu dan tempat kerja (Thomas \& Ganster, 1995) dan mengurangi konflik kerja-keluarga (Kossek \& Ozeki, 1998). Ada juga bukti yang menunjukkan bahwa pengusaha yang menerapkan program work - life balance dan menawarkan pengaturan kerja yang fleksibel cenderung memiliki keunggulan kompetitif di pasar karyawan (Morgan, 2009).

$\mathrm{H}_{1}$ : Work - life balance berpengaruh terhadap turnover intentions 


\section{Hubungan antara Kepuasan Kerja dengan Turnover intentions}

Meskipun kepuasan kerja telah ditemukan sebagai prediktor yang cukup konsisten dari turnover intentions, kekuatan kepuasan - keinginan untuk meninggalkan hubungan bervariasi sesuai dengan setiap pengaturan. Selain itu, sedikit pekerjaan telah dilakukan menggunakan subjek profesional dalam konteks Asia Tenggara (misalnya, Aryee dan Wyatt, 1991; Chan dan Morrison, 2000). Kepuasan kerja telah berulang kali diidentifikasi sebagai alasan utama mengapa karyawan meninggalkan pekerjaan mereka (Barak et al., 2001). Banyak penelitian (misalnya, Mobley et al., 1978; Price dan Mueller, 1981; Shore dan Martin, 1989; Aryee dan Wyatt, 1991; Hellman, 1997; Chan dan Morrison, 2000; Ghiselli et al., 2001; McBey dan Karakowsky, 2001) telah melaporkan hubungan negatif yang signifikan antara kepuasan kerja dan niat untuk meninggalkan organisasi. (Mahdi, Zin, Nor, Sakat, \& Naim, 2016)

Penelitian dari berbagai negara telah menegaskan bahwa kepuasan kerja dan komitmen organisasi adalah prediktor yang signifikan secara statistik dari absensi atau turnover karyawan, atau niat mereka untuk berhenti (Lee, T.Y., et al., 2009). Jadi, untuk mengurangi niat karyawan baru untuk pergi, manajer lapangan harus segera mengatasi masalah meningkatkan kepuasan kerja dan komitmen organisasi karyawan baru. (Nkomo \& Thwala, 2018) Olusegun (2015), menemukan bahwa ada hubungan yang signifikan antara kepuasan kerja dan turnover intentions. (Azeez, Jayeoba, \& Sdeoye, 2016)

$\mathrm{H}_{2}$ : Kepuasan kerja berpengaruh terhadap turnover intentions

\section{Hubungan antara Work Engagement dengan Turnover Intentions}

Penelitian menunjukkan bahwa work engagement telah muncul di dunia kerja saat ini sebagai konstruksi yang dapat secara signifikan mempengaruhi turnover intentions karyawan (Halbesleben \& Wheeler, 2008; Mitchell, Holtom \& Lee, 2001a). Secara khusus, karyawan dengan tingkat work engagement rendah lebih cenderung memiliki niat yang lebih tinggi untuk meninggalkan organisasi, serta benar-benar meninggalkannya (Mitchell, Holtom, Lee, Sablynski \& Erez, 2001b). (Agoi, 2015)

Penelitian sebelumnya telah menunjukkan bahwa work engagement secara positif terkait dengan kinerja (Bakker, Demerouti, \& Verbeke, 2004), dan kemampuan kerja (Airila, Hakanen, Punakallio, Lusa \& Luukkonen, 2012) dan berhubungan negatif dengan absensi (Schaufeli, Bakker, \& Van Rhenen, 2009) perilaku menyimpang (Shantz, Alfes, Truss, \& Soane, 2013; Sulea et al., 2012 ) dan turnover intentions (Halbesleben, 2010). Menurut Shantz, Alfes \& Latham (2016), yang melakukan penelitian dari sebuah organisasi manufaktur di Inggris tentang hubungan antara work engagement, komitmen organisasi dan turnover intentions. Hasilnya menunjukkan bahwa tingkat work engagement yang rendah dikaitkan dengan tingkat turnover intentions yang lebih tinggi ketika karyawan tersebut merasa bahwa mereka tidak didukung oleh organisasi mereka. (Zhao \& Zhao, 2017)

$\mathrm{H}_{3} \quad$ : Work engagement berpengaruh terhadap turnover intentions

\section{Pengaruh Moderasi Mentoring terhadap Turnover Intentions}

Studi empiris umumnya menegaskan bahwa mentoring berhubungan negatif dengan keinginan berpindah (Viator dan Scandura, 1991) menemukan bahwa karyawan yang memiliki hubungan mentoring informal dilaporkan memiliki niat yang lebih rendah untuk berpindah dibandingkan mereka yang tanpa hubungan. Penelitian baru- 
baru ini juga telah membentuk hubungan negatif antara mentoring dan protege terhadap keinginan berpindah (Eby et al., 2013).

$\mathrm{H}_{4}$ : Mentoring berpengaruh terhadap turnover intentions

Menurut Knippenberg, B.V., Steensma, H. (2003) menyarankan bahwa harapan interaksi masa depan antara supervisor dan staff akan menurunkan penggunaan taktik kekerasan karena ini dapat membahayakan hubungan dan membuatnya kurang menarik. Penelitian sebelumnya telah membuktikan dampak mentoring dalam pengembangan profesional dan pribadi karyawan muda di organisasi. Penelitian yang ada telah menunjukkan bahwa mentoring adalah salah satu cara terbaik dalam pembelajaran organisasi dan telah membuktikan hasil positif dengan dukungan (Simmonds, D., Zammit Lupi, A.M., 2010) dan kepuasan kerja (Seibert, S., 1999).

$\mathrm{H}_{5}$ : Work - life balance yang dimoderasi dengan mentoring berpengaruh terhadap turnover intentions

Program mentoring dalam organisasi dapat membantu dalam meningkatkan kinerja dan mentransfer pengetahuan, dan mengarah pada kepuasan kerja yang lebih tinggi dan retensi karyawan, yang menghasilkan produktivitas bisnis yang lebih tinggi. (Nkomo \& Thwala, 2018)

$\mathrm{H}_{6}$ : Kepuasan kerja yang dimoderasi dengan mentoring berpengaruh terhadap turnover intentions

Telah dicatat bahwa anak didik yang menerima dukungan mentoring mampu menunjukkan kinerja pekerjaan yang lebih baik dan pengembangan karir (Liden, R.C., et al., 1997) dan mengurangi turnover intentions di antara karyawan dalam bimbingan organisasi (Beverly, K. \& Sharon, J.E., 2005). Joiner dkk., menemukan bahwa program mentoring yang sukses berdampak positif terhadap komitmen organisasi karyawan dan mengurangi turnover intentions. (Ragins et al., 2000) menunjukkan bahwa para anak didik atau protégés mengalami tingkat komitmen organisasi yang lebih besar dibandingkan dengan karyawan yang tidak dibimbing atau di mentoring. (Chun, Sosik, \& Yun, 2012)

Penggunaan hubungan mentoring yang ditujukan untuk pengembangan karyawan meningkat pesat dalam organisasi (Noe, R.A., et al., 2002). Beberapa manfaat dari hubungan mentoring yang terdiri dari mobilitas karir dan kemajuan, kepuasan karir, lebih banyak promosi dan kompensasi yang lebih tinggi, dan retensi yang lebih besar (Scandura, T.A. \& Ragins, B.R., 1993). (Nkomo \& Thwala, 2018)

$\mathrm{H}_{7}$ : Work engagement yang dimoderasi dengan mentoring berpengaruh terhadap turnover intentions

\section{METODE}

Penelitian ini bermaksud menguji Pengaruh Work - Life Balance, Kepuasan Kerja, dan Work Engagement terhadap Turnover Intentions, dan Mentoring sebagai variabel Moderating. Penelitian ini menggunakan pendekatan kuantitatif dengan desain ex post facto. Sehingga dalam penelitian ini tidak menggunakan perlakuan terhadap variable penelitian, melainkan menguji fakta-fakta yang telah terjadi dan pernah dilakukan oleh subject penelitian.

Dalam penelitian ini terdapat tiga variabel independen (variabel eksogen), satu variabel moderating, dan satu variabel dependen (variabel endogen). Sebagai variabel 
independen yaitu: Work - Life Balance $\left(\mathrm{X}_{1}\right)$, Kepuasan Kerja $\left(\mathrm{X}_{2}\right)$, dan Work Engagement $\left(\mathrm{X}_{3}\right)$, dengan dimoderasi Mentoring $\left(\mathrm{X}_{4}\right)$ terhadap Turnover Intentions $(\mathrm{Y})$ sebagai variable dependennya.

Jenis dan sumber data dalam penelitian ini adalah data primer. Data primer adalah sumber data yang langsung memberikan data kepada pengumpul data (Sugiyono, 2016). Data primer dalam penelitian ini diperoleh secara langsung dari objek penelitian dengan cara membagi angket kepada karyawan Hotel Dafam Semarang, menarik angket yang telah disebar, dan dilakukan scoring terhadap angket.

Populasi adalah wilayah generalisasi yang terdiri atas objek atau subjek yang mempunyai kualitas dan karakteristik tertentu yang ditetapkan oleh peneliti untuk dipelajari dan kemudian ditarik kesimpulannya (Sugiyono, 2016). Populasi dalam penelitian ini meliputi semua karyawan pada Hotel Dafam Semarang, yaitu karyawan Generasi X dan Generasi Y; dengan tahun kelahiran antara tahun 1960 - 1979 dan tahun 1980 - 1995 (Andrea et al., 2016). Teknik sampling yang digunakan di sini adalah purposive sampling, dimana teknik pengambilan sampel dengan pertimbangan tertentu dari anggota populasi yang menjadi sampel penelitian (Sugiyono, 2016). Dimana sample diambil dari 43 karyawan yang sudah menikah.

Metode pengumpulan data dalam penelitian ini adalah metode angket atau kuesioner, dan skala pengumpulan data dengan skala likert. Menurut Sugiyono (2009), kuesioner mengungkapkan merupakan teknik pengumpulan data yang dilakukan dengan cara memberikan seperangkat pertanyaan atau pernyataan tertulis kepada responden untuk dijawab.

Kuesioner dibuat untuk mendapatkan data yang bersifat interval dan diberi score atau nilai. Untuk dapat dijawab dengan mudah oleh responden, maka responden cukup memberikan tanda $(\sqrt{ })$ pada skala 1-10 yang sudah tersedia, dimana skala 1 diartikan sebagai "sangat tidak setuju" dan skala 10 diartikan sebagai "sangat setuju".

Dalam penelitian ini analisis data menggunakan pendekatan Smart-PLS (Partial Least Square). PLS adalah model persamaan SEM (Structural Equation Modeling) yang berbasis komponen atau varian. Menurut Ghozali (2015), PLS merupakan pendekatan alternatif yang bergeser dari pendekatan SEM berbasis kovarian menjadi berbasis varian. SEM yang berbasis kovarian umumnya menguji teori sedangkan PLS lebih bersifat predictive model. PLS merupakan metode analisis yang powerfull (Ghozali, 2015), karena tidak didasarkan pada banyak asumsi. Misalnya: data harus terdistribusi normal, sampel tidak harus besar. Selain dapat digunakan untuk mengkonfirmasi teori, PLS juga dapat digunakan untuk menjelaskan ada tidaknya hubungan antar variabel laten. PLS dapat sekaligus menganalisis konstruk yang dibentuk dengan indikator reflektif dan formatif.

Model pengukuran (Outer Model) digunakan untuk menilai validitas dan realibilitas model. Uji validitas dilakukan untuk mengetahui kemampuan instrumen penelitian mengukur apa yang seharusnya diukur (Cooper dan Schindler dalam Jogiyanto dan Abdillah 2009). Sedangkan uji reliablitas digunakan untuk mengukur konsistensi alat ukur dalam mengukur suatu konsep atau dapat juga digunakan untuk mengukur konsistensi responden dalam menjawab item pernyataan dalam kuesioner atau instrument penelitian.

Outer model atau outer relation mendefinisikan bagaimana setiap blok indikator berhubungan dengan variable latennya. Model ini menspesifikasi hubungan antar variable laten dengan indikatornya atau dapat dikatakan bahwa outer model mendefinisikan hubungan setiap indikator dengan variable latennya. 
Rule of thumb yang biasa digunakan untuk menilai Convergent validity yaitu nilai loading factor harus lebih dari 0,7 untuk penelitian yang bersifat confirmatory dan nilai loading factor antara 0,6 - 0,7 untuk penelitian yang bersifat exploratory. Namun demikian untuk penelitian tahap awal dari pengembangan skala pengukuran nilai loading factor 0,5 sampai 0,6 masih dianggap cukup (Chin, 1998 dalam Ghozali, 2015).

Metode untuk menilai discriminant validity adalah membandingkan nilai square root of Average Variance Extracted (AVE) setiap konstruk dengan korelasi antara konstruk lainnya dalam model. Apabila nilai akar $A V E$ lebih tingi daripada nilai korelasi di antara variabel laten, maka discriminant validity dapat dianggap tercapai. Discriminant validity dapat dikatakan tercapai apabila nilai $A V E$ lebih besar dari 0,5. (Fornnel dan Larcker, 1981) (Ghozali, 2015).

Uji reliabilitas dapat dilihat dari nilai Composite reliability $(\rho c)$ dan nilai Cronbach's Alpha. Suatu variabel laten dapat dikatakan mempunyai reliabilitas yang baik apabila nilai Composite reliability >0,7 dan nilai Cronbach's Alpha >0,6. (Ghozali, 2015)

Menurut Vincenzo (2010) Uji pada model struktural dilakukan untuk menguji hubungan antara konstruk laten. Ada beberapa uji untuk model struktural yaitu: (a) $R$ Square pada konstruk endogen. Nilai $R$-Square adalah koefisien determinasi pada konstruk endogen. Menurut Chin (1998), nilai R-Square sebesar 0.67 (kuat), 0.33 (moderat) dan 0.19 (lemah); (b) Prediction relevance ( $Q$-square) atau dikenal dengan predictive sample reuse. Uji ini dilakukan untuk mengetahui kapabilitas prediksi dengan prosedur blinfolding. Apabila nilai yang didapatkan 0.02 (lemah), 0.15 (moderat) dan 0.35 (kuat). Nilai Q-square > 0 menunjukkan model memilki predictive relevance; sebaliknya jika niali Q-square $\leq 0$ menunjukkan model kurang memilki predictive relevance. Perhitungan $Q-S q u a r e ~ d i l a k u k a n$ dengan rumus: $Q^{2}=1-\left(1-R_{1}^{2}\right)\left(1-R_{2}^{2}\right)$ ... $\left(1-\mathrm{R}_{\mathrm{p}}{ }^{2}\right)$, Dimana $\mathrm{R}_{1}{ }^{2}, \mathrm{R}_{2}{ }^{2}, \ldots, \mathrm{R}_{\mathrm{p}}{ }^{2}$ adalah $\mathrm{R}$-Square variabel endogen dalam model persamaan. Besaran $\mathrm{Q}^{2}$ memilki nilai dengan rentang $0<\mathrm{Q}^{2}<1$, dimana semakin mendekati 1 berarti model semakin baik.

Jogiyanto dan Abdillah (2009) menjelaskan bahwa ukuran signifikansi keterdukungan hipotesis dapat digunakan perbandingan nilai T-table dan T-statistic. Jika $T$-statistic lebih tinggi dibandingkan nilai $T$-table, berarti hipotesis terdukung atau diterima. Dalam penelitian ini digunakan tingkat keyakinan 95 persen (alpha 95 persen) maka nilai $T$-table untuk hipotesis adalah >1,960. Analisis PLS (Partial Least Square) yang digunakan dalam penelitian ini dilakukan dengan menggunakan program SmartPLS versi 3.2.7.

\section{HASIL DAN PEMBAHASAN}

\section{Pengujian Outer Model atau Measurement Model}

Terdapat tiga kriteria di dalam penggunaan teknik analisa data dengan SmartPLS untuk menilai outer model yaitu Convergent Validity, Discriminant Validity dan Composite Reliability. Convergent validity dari model pengukuran dengan refleksif indikator dinilai berdasarkan korelasi antara item score / component score yang diestimasi dengan Soflware PLS. Ukuran refleksif individual dikatakan tinggi jika berkorelasi lebih dari 0,70 dengan konstruk yang diukur. Namun menurut Chin, 1998 (dalam Ghozali, 2006) untuk penelitian tahap awal dari pengembangan skala pengukuran nilai loading 0,5 sampai 0,6 dianggap cukup memadai. Dalam penelitian ini akan digunakan batas loading factor sebesar 0,60. 


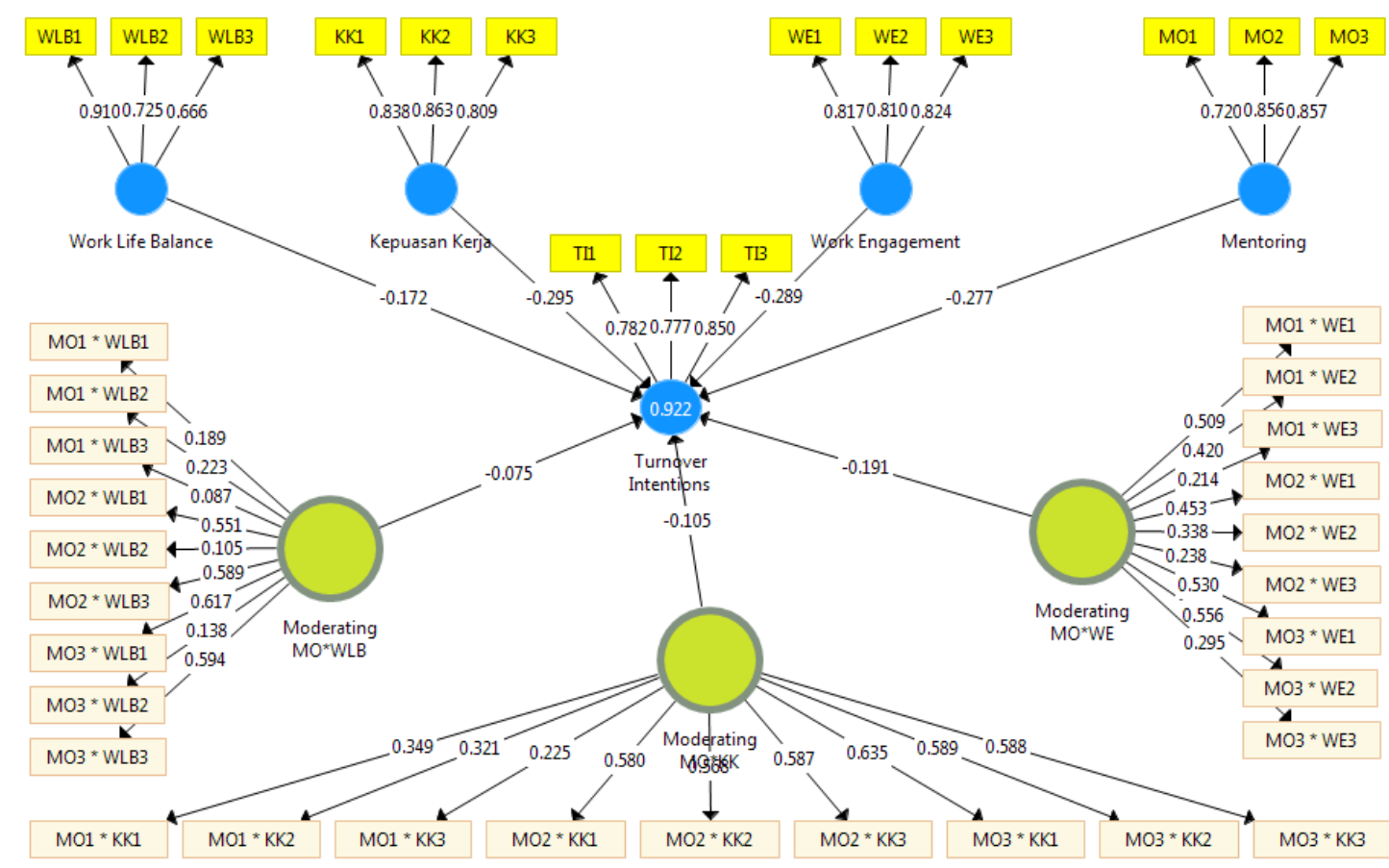

Gambar 1

Outer Loading

Tabel 1

Outer Loadings (Measurement Model)

\begin{tabular}{|c|c|}
\hline \multicolumn{2}{|c|}{ Work Life Balance } \\
\hline WLB1 & 0,910 \\
\hline WLB2 & 0,725 \\
\hline WLB3 & 0,666 \\
\hline \multicolumn{2}{|c|}{ Kepuasan Kerja } \\
\hline KK1 & 0,838 \\
\hline KK2 & 0,863 \\
\hline KK3 & 0,809 \\
\hline \multicolumn{2}{|c|}{ Work Engagement } \\
\hline WE1 & 0,817 \\
\hline WE2 & 0,810 \\
\hline WE3 & 0,824 \\
\hline \multicolumn{2}{|c|}{ Mentoring } \\
\hline MO1 & 0,720 \\
\hline MO2 & 0,856 \\
\hline MO3 & 0,857 \\
\hline \multicolumn{2}{|c|}{ Turnover Intentions } \\
\hline TI1 & 0,782 \\
\hline TI2 & 0,777 \\
\hline TI3 & 0,850 \\
\hline
\end{tabular}

Sumber: Data primer yang diolah (2019) 
Dari Tabel 1, nilai outer model atau korelasi antara konstruk dengan variabel sudah memenuhi convergen validity karena sudah di atas nilai loading factor 0,60.

\section{Discriminant Validity}

Discriminant validity dilakukan untuk memastikan bahwa setiap konsep dari masing variabel laten berbeda dengan variabel lainnya. Model mempunyai discriminant validity yang baik jika setiap nilai loading dari setiap indikator dari sebuah variabel laten memiliki nilai loading yang paling besar dengan nilai loading lain terhadap variabel laten lainnya. Hasil pengujian discriminant validity diperoleh sebagai berikut:

Tabel 2

Nilai Discriminat Validity

(Cross Loading)

\begin{tabular}{|c|c|c|c|c|c|}
\hline Variable & WLB & KK & WE & MO & TI \\
\hline WLB1 & 0,910 & 0,589 & 0,737 & 0,557 & $-0,716$ \\
\hline WLB2 & 0,725 & 0,471 & 0,546 & 0,425 & $-0,537$ \\
\hline WLB3 & 0,666 & 0,536 & 0,437 & 0,402 & $-0,505$ \\
\hline KK1 & 0,639 & 0,838 & 0,562 & 0,464 & $-0,665$ \\
\hline KK2 & 0,649 & 0,863 & 0,558 & 0,496 & $-0,716$ \\
\hline KK3 & 0,418 & 0,809 & 0,438 & 0,498 & $-0,605$ \\
\hline WE1 & 0,599 & 0,421 & 0,817 & 0,515 & $-0,648$ \\
\hline WE2 & 0,600 & 0,465 & 0,810 & 0,495 & $-0,625$ \\
\hline WE3 & 0,652 & 0,632 & 0,824 & 0,578 & $-0,699$ \\
\hline MO1 & 0,483 & 0,519 & 0,396 & 0,720 & $-0,585$ \\
\hline MO2 & 0,561 & 0,505 & 0,651 & 0,856 & $-0,697$ \\
\hline MO3 & 0,428 & 0,401 & 0,521 & 0,857 & $-0,673$ \\
\hline TI1 & $-0,544$ & $-0,666$ & $-0,658$ & $-0,640$ & 0,782 \\
\hline TI2 & $-0,588$ & $-0,665$ & $-0,522$ & $-0,615$ & 0,777 \\
\hline TI3 & $-0,709$ & $-0,592$ & $-0,752$ & $-0,680$ & 0,850 \\
\hline
\end{tabular}

Sumber: Data primer yang diolah (2019)

Dari tabel 2 dapat dilihat bahwa nilai loading factor untuk setiap indikator dari masing-masing variabel laten memiliki nilai loading factor yang paling besar dibanding nilai loading factor jika dihubungkan dengan variabel laten lainnya. Hal ini berarti bahwa setiap variabel laten memiliki discriminant validity yang baik.

\section{Average Variance Extracted (AVE)}

Kriteria validity juga dapat dilihat dari nilai Average Variance Extracted (AVE) dari masing-masing konstruk. Konstruk dikatakan memiliki validitas yang tinggi jika nilai AVE berada diatas 0,50. Pada Tabel 3 akan disajikan nilai untuk seluruh variabel. 
Tabel 3

Average Variance Extracted

\begin{tabular}{|c|c|}
\hline Variable & $\begin{array}{c}\text { Average Variance } \\
\text { Extracted (AVE) }\end{array}$ \\
\hline WLB & 0,599 \\
\hline KK & 0,700 \\
\hline WE & 0,667 \\
\hline MO & 0,662 \\
\hline TI & 0,646 \\
\hline
\end{tabular}

Sumber: Data primer yang diolah (2019)

\section{Uji Reliabilitas}

Uji reliabilitas dapat dilihat dari nilai Cronbach's Alpha dan nilai Composite reliability. Suatu variabel laten dapat dikatakan mempunyai reliabilitas yang baik apabila nilai Cronbach's Alpha >0,6 dan nilai Composite reliability >0,7. Pada Tabel 4 akan disajikan nilai untuk seluruh variabel.

\section{Tabel 4}

Cronbach's Alpha dan Composite Reliability

\begin{tabular}{|c|c|c|}
\hline Variable & Cronbach's Alpha & Composite Reliability \\
\hline WLB & 0,654 & 0,815 \\
\hline KK & 0,786 & 0,875 \\
\hline WE & 0,751 & 0,857 \\
\hline MO & 0,742 & 0,854 \\
\hline TI & 0,725 & 0,845 \\
\hline MO*WLB & 0,665 & 0,640 \\
\hline MO*KK & 0,823 & 0,835 \\
\hline MO*WE & 0,624 & 0,722 \\
\hline
\end{tabular}

Sumber: Data primer yang diolah (2019)

Berdasarkan Tabel 4 dapat disimpulkan bahwa semua konstruk memenuhi kriteria reliabilitas. Hal ini ditunjukkan dengan nilai Cronbach's Alpha di atas 0,60 dan nilai Composite Reliability di atas 0,70 sebagaimana kriteria yang direkomendasikan.

\section{Pengujian Inner Model atau Model Struktural}

Pengujian inner model atau model struktural dilakukan untuk melihat hubungan antara konstruk, nilai signifikansi dan $R$-square dari model penelitian. Model struktural dievaluasi dengan menggunakan $R$-square untuk konstruk dependen uji $\mathrm{T}$ serta signifikansi dari koefisien parameter jalur struktural.

Dalam menilai model dengan PLS dimulai dengan melihat $R$-square untuk setiap variabel laten dependen. Tabel 5 merupakan hasil estimasi R-square dengan menggunakan SmartPLS. 
Tabel 5

R-Square

\begin{tabular}{|c|c|}
\hline Variable & R-Square \\
\hline TI & 0,922 \\
\hline
\end{tabular}

Sumber: Data primer yang diolah (2019)

\section{Q-Square}

Pengujian Inner model dapat dilakukan dengan melihat nilai $\mathrm{Q}^{2}$ (predictive relevance). Untuk menghitung $\mathrm{Q}^{2}$ dapat digunakan rumus

$$
\begin{aligned}
& \mathrm{Q}^{2}=1-\left(1-\mathrm{R}_{1}{ }^{2}\right)\left(1-\mathrm{R}_{2}{ }^{2}\right) \ldots \ldots\left(1-\mathrm{R}_{\mathrm{p}}{ }^{2}\right) \ldots \\
& \mathrm{Q}^{2}=1-(1-0,922) \\
& \mathrm{Q}^{2}=1-(0,078) \\
& \mathrm{Q}^{2}=0,922
\end{aligned}
$$

Dari pengujian $\mathrm{R}^{2}$ dan $\mathrm{Q}^{2}$ terlihat bahwa model yang dibentuk adalah kuat, sehingga pengujian hipotesa dapat dilakukan.

\section{Pengujian Hipotesis}

Dalam PLS pengujian secara statistik setiap hubungan yang dihipotesiskan dilakukan dengan menggunakan simulasi. Dalam hal ini dilakukan metode bootstrapping terhadap sampel. Pengujian dengan bootstrapping juga dimaksudkan untuk meminimalkan masalah ketidaknormalan data penelitian. Hasil pengujian dengan bootstrapping dari analisis PLS dapat dilihat pada Tabel 6:

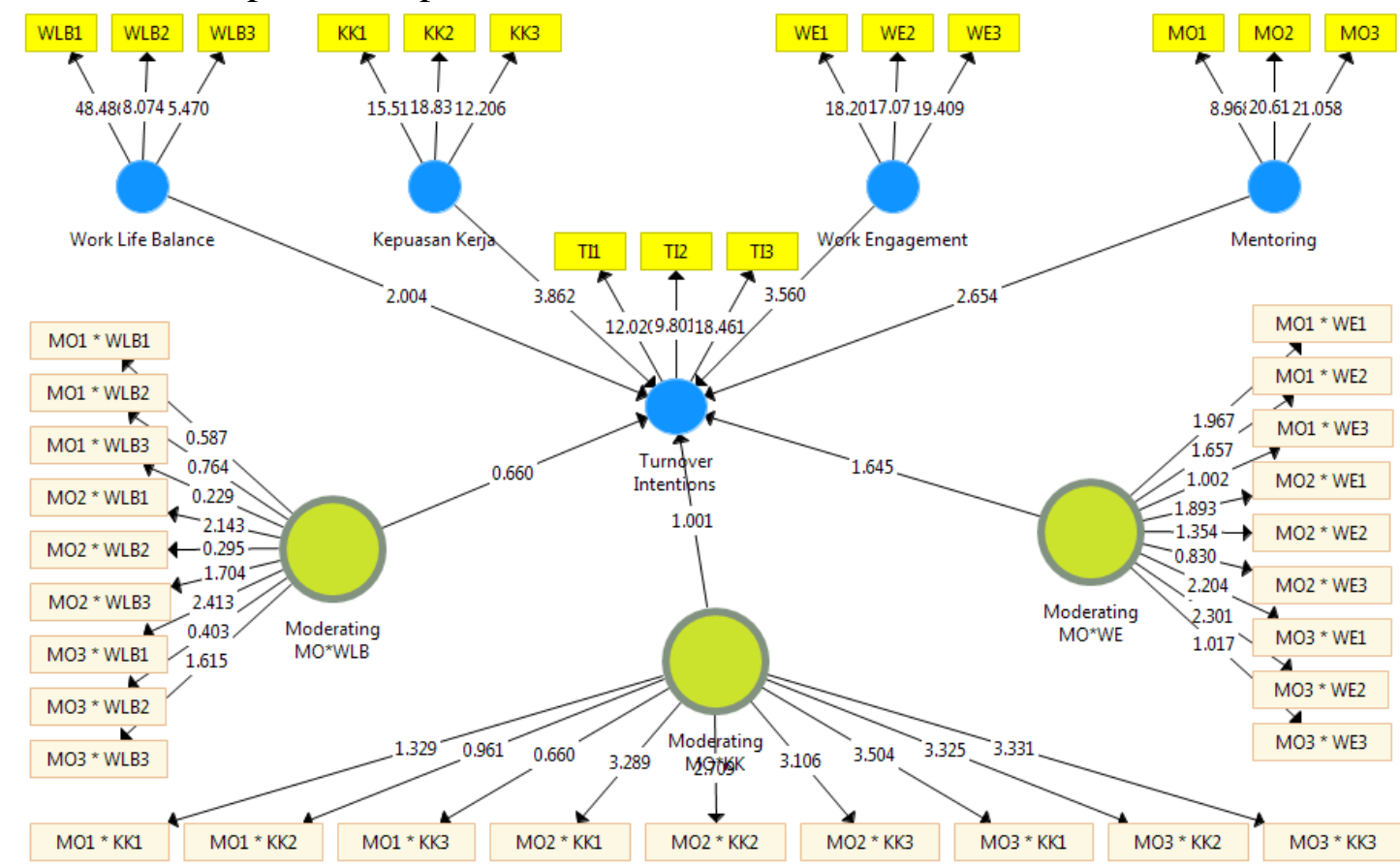

Gambar 2

Analisis Struktural hasil Bootstrapping 
Tabel 6

Result For Inner Weights

\begin{tabular}{|c|c|c|c|c|c|}
\hline & $\begin{array}{c}\text { Original } \\
\text { Sample } \\
(\mathbf{O})\end{array}$ & $\begin{array}{c}\text { Sample } \\
\text { Mean } \\
(\mathbf{M})\end{array}$ & $\begin{array}{c}\text { Standard } \\
\text { Deviation } \\
\text { (STDEV) }\end{array}$ & $\begin{array}{c}\text { T Statistic } \\
(\mid \mathbf{O} \text { (STDEV) }\end{array}$ & $\begin{array}{c}\text { P } \\
\text { Value }\end{array}$ \\
\hline WLB > TI & $-0,172$ & $-0,140$ & 0,086 & 2.004 & 0,046 \\
\hline KK > TI & $-0,295$ & $-0,295$ & 0,076 & 3,862 & 0,000 \\
\hline WE > TI & $-0,289$ & $-0,303$ & 0,081 & 3,560 & 0,000 \\
\hline MO > TI & $-0,277$ & $-0,283$ & 0,104 & 2,654 & 0,008 \\
\hline WLB*MO > TI & $-0,075$ & $-0,085$ & 0,113 & 0,660 & 0,510 \\
\hline KK*MO > TI & $-0,105$ & $-0,092$ & 0,105 & 1,001 & 0,318 \\
\hline WE*MO > TI & $-0,191$ & $-0,176$ & 0,116 & 1,645 & 0,101 \\
\hline \multicolumn{7}{|c|}{ Sumber: Data primer yang diolah (2019) } \\
\hline
\end{tabular}

\section{Pengujian Hipotesis 1 (Work - life balance berpengaruh terhadap Turnover Intentions)}

Berdasarkan hasil output Tabel 6, nilai original sample adalah sebesar $-1,172$ dengan signifikansi $<0,05$, dan nilai $\mathrm{T}$ statistik untuk Work - Life Balance (WLB) terhadap Turnover Intentions (TI) sebesar 2,004 > T tabel $(1,960)$. Nilai original sample menunjukan nilai negatif mengindikasikan bahwa Work - Life Balance (WLB) berpengaruh negatif terhadap Turnover Intentions (TI). Dengan demikian $\mathbf{H}_{1}$ pada penelitian diterima.

\section{Pengujian Hipotesis 2 (Kepuasan Kerja berpengaruh terhadap Turnover Intentions)}

Berdasarkan hasil output Tabel 6, nilai original sample adalah sebesar -0,295 dengan signifikansi $<0,05$, dan nilai $\mathrm{T}$ statistik untuk Kepuasan Kerja terhadap Turnover Intentions (TI) sebesar 3,862 > T tabel $(1,960)$. Nilai original sample menunjukan nilai negatif mengindikasikan bahwa Kepuasan Kerja berpengaruh negatif terhadap Turnover Intentions (TI). Dengan demikian $\mathrm{H}_{2}$ pada penelitian diterima.

\section{Pengujian Hipotesis 3 (Work Engagement berpengaruh terhadap Turnover Intentions)}

Berdasarkan hasil output Tabel 6, nilai original sample adalah sebesar -0,289 dengan signifikansi $<0,05$, dan nilai $\mathrm{T}$ statistik untuk Work Engagement terhadap Turnover Intentions (TI) sebesar 3,560 > T tabel $(1,960)$. Nilai original sample menunjukan nilai negatif mengindikasikan bahwa Work Engagement berpengaruh negatif terhadap Turnover Intentions (TI). Dengan demikian $\mathbf{H}_{3}$ pada penelitian diterima.

\section{Pengujian Hipotesis 4 (Mentoring berpengaruh terhadap Turnover Intentions)}

Berdasarkan hasil output Tabel 6, nilai original sample adalah sebesar -0,277 dengan signifikansi $<0,05$, dan nilai $\mathrm{T}$ statistik untuk Mentoring terhadap Turnover Intentions (TI) sebesar 2,654 > T tabel $(1,960)$. Nilai original sample menunjukan nilai negatif mengindikasikan bahwa Mentoring berpengaruh negatif terhadap Turnover Intentions $(\mathrm{TI})$. Dengan demikian $\mathrm{H}_{4}$ pada penelitian diterima. 
Pengujian Hipotesis 5 (Work - Life Balance yang dimoderasi dengan Mentoring berpengaruh terhadap Turnover Intentions)

Berdasarkan hasil output Tabel 6, nilai original sample adalah sebesar -0,075 dengan signifikansi $>0,05$, dan nilai T statistik untuk Work - Life Balance (WLB) yang dimoderasi dengan Mentoring terhadap Turnover Intentions (TI) sebesar 0,660 < T tabel $(1,960)$. Nilai original sample menunjukan nilai negatif mengindikasikan bahwa WorkLife Balance (WLB) yang dimoderasi dengan Mentoring berpengaruh negatif terhadap Turnover Intentions (TI). Dengan demikian $\mathbf{H}_{5}$ pada penelitian ditolak.

\section{Pengujian Hipotesis 6 (Kepuasan Kerja yang dimoderasi dengan Mentoring berpengaruh terhadap Turnover Intentions)}

Berdasarkan hasil output Tabel 6, nilai original sample adalah sebesar -0,105 dengan signifikansi $>0,05$, dan nilai T statistik untuk Kepuasan Kerja yang dimoderasi dengan Mentoring terhadap Turnover Intentions (TI) sebesar 1,001 $<\mathrm{T}$ tabel $(1,960)$. Nilai original sample menunjukan nilai negatif mengindikasikan bahwa Kepuasan Kerja yang dimoderasi dengan Mentoring berpengaruh negatif terhadap Turnover Intentions (TI). Dengan demikian $\mathbf{H}_{6}$ pada penelitian ditolak.

\section{Pengujian Hipotesis 7 (Work Engagement yang dimoderasi dengan Mentoring berpengaruh terhadap Turnover Intentions)}

Berdasarkan hasil output Tabel 6, nilai original sample adalah sebesar -0,191 dengan signifikansi $>0,05$, dan nilai $\mathrm{T}$ statistik untuk Work Engagement yang dimoderasi dengan Mentoring terhadap Turnover Intentions (TI) sebesar 1,645 < T tabel (1,960). Nilai original sample menunjukan nilai negatif mengindikasikan bahwa Work Engagement yang dimoderasi dengan Mentoring berpengaruh negatif terhadap Turnover Intentions (TI). Dengan demikian $\mathrm{H}_{7}$ pada penelitian ditolak.

\section{Pembahasan}

Work - life balance berpengaruh terhadap Turnover Intentions

Penelitian ini mendapatkan hasil variabel Work - Life Balance berpengaruh negatif signifikan terhadap vaiabel Turnover Intention. Hal ini sejalan dengan penelitian Downes dan Koekemoer (2011), organisasi yang banyak berinvestasi dalam hal WorkLife Balance menurunkan turnover karyawan. Chemirmir J. M. et al., 2018 menyatakan: manfaat Work - Life Balance untuk organisasi termasuk pengurangan tingkat ketidakhadiran, peningkatan produktivitas, dan peningkatan retensi karyawan.

Waktu bersama keluarga adalah kebutuhan dasar yang diperlukan setiap manusia, dalam hal ini karyawan Hotel Dafam Semarang juga perlu berinteraksi dalam kehidupan keluarganya di luar jam kantor. Kondisi ini sudah terakomodir dengan baik oleh perusahaan. begitu juga waktu untuk istirahat, makan, dan beribadah sudah sesuai dengan kebutuhan karyawan. Hal inilah yang bisa menekan angka perputaran karyawan I turnover intentions.

\section{Kepuasan Kerja berpengaruh terhadap Turnover Intentions}

Penelitian ini mendapatkan hasil variabel Kepuasan Kerja berpengaruh negatif signifikan terhadap vaiabel Turnover Intention. Hal ini sejalan dengan penelitian Sidharta, N. (2011) yang menyatakan bahwa kepuasan kerja berdampak negatif signifikan terhadap turnover intentions. 
Interaksi dengan rekan kerja yang harmonis dalam menyelesaikan perkejaan membuat karyawan nyaman dalam bekerja, dan secara tidak langsung membuat karyawan merasa mencintai pekerjaanya. Hal tersebut membuat karyawan memilih untuk menghabiskan sisa karisnya di Hotel Dafam Semarang.

\section{Work Engagement berpengaruh terhadap Turnover Intentions}

Hasil penelitian ini mendapatkan hasil variabel Work Engagement berpengaruh negatif signifikan terhadap vaiabel Turnover Intention. Hal ini sejalan dengan penelitian Merissa, B. (2018), yang mengemukakan work engagement atau keterlibatan kerja untuk dikaitkan secara negatif dengan turnover intentions.

Karyawan merasa semangatnya (vigor) terpacu ketika bekerja di Hotel Dafam Semarang, mereka juga menghayati (absorption) dalam melakukan pekerjaannya. Karyawan juga cukup berdedikasi (dedication) dalam menjalankan tugas dan tanggung jawabnya. Schaufeli \& Bakker (2004) sebelumnya menyatakan bahwa sikap positif terhadap pekerjaan, seperti kepuasan kerja, keterlibatan kerja, organisasi komitmen dan turnover intentions rendah, tampaknya terkait dengan work engagement.

\section{Mentoring berpengaruh terhadap Turnover Intentions}

Hasil penelitian ini mendapatkan hasil variabel Mentoring berpengaruh negatif signifikan terhadap vaiabel Turnover Intention. Hal ini sejalan dengan penelitian Hemastiti, G. (2017), yang menyatakan bahwa mentoring berpengaruh negatif terhadap turnover intentions.

Adanya dukungan instrumental dan dukungan psikososial, membuat karyawan merasa nyaman dalam bekerja. Begitu juga dukungan atasan yang membuat karyawan merasa dihargai ketika bekerja.

\section{Work - life balance yang dimoderasi Mentoring berpengaruh terhadap Turnover Intentions}

Hasil penelitian ini mendapatkan hasil variabel Work - Life Balance yang dimoderasi Mentoring berpengaruh negatif tidak signifikan terhadap vaiabel Turnover Intention. Faktor Work - Life Balance lebih dominan dirasakan bagi karyawan Hotel Dafam Semarang, sehingga mereka lebih memilih bertahan untuk tetap bekerja di Hotel Dafam Semarang.

\section{Kepuasan Kerja yang dimoderasi Mentoring berpengaruh terhadap Turnover Intentions}

Hasil penelitian ini mendapatkan hasil variabel Kepuasan Kerja yang dimoderasi Mentoring berpengaruh negatif tidak signifikan terhadap vaiabel Turnover Intentions. Nkomo \& Thwala (2018) menyatakan program mentoring dalam organisasi dapat membantu dalam meningkatkan kinerja dan mentransfer pengetahuan, dan mengarah pada kepuasan kerja yang lebih tinggi dan retensi karyawan, yang menghasilkan produktivitas bisnis yang lebih tinggi. Faktor kenyamanan dalam bekerja dan menyenangi pekerjaan lebih dirasakan manfaatnya bagi karyawan Hotel Dafam Semarang, sehingga mereka lebih memilih bertahan untuk tetap bekerja di Hotel Dafam Semarang. 


\section{Work Engagement yang dimoderasi Mentoring berpengaruh terhadap Turnover Intentions}

Hasil penelitian ini mendapatkan hasil variabel Work Engagement yang dimoderasi Mentoring berpengaruh negatif tidak signifikan terhadap vaiabel Turnover Intention. Baran, M (2017) menyatakan bahwa orang yang terlibat dalam proses mentoring menunjukkan engagement yang lebih besar dalam pekerjaan. Ketiga faktor Work Engagement yaitu semangat dalam bekerja, dedikasi dalam bekerja, dan menghayati pekerjaan (vigor, dedication, absorption) lebih mendominasi perasaan karyawan, sehingga mereka lebih terlibat dengan pekerjaannya tersebut.

\section{PENUTUP}

\section{Kesimpulan}

Didasarkan pada hasil analisis maka terdapat pengaruh negatif signifikan antara Work - Life Balance terhadap Turnover Intentions. Work - Life Balance bisa diartikan sebagai keseimbangan antara tuntutan pekerjaan dan kebutuhan untuk berkumpul bersama keluarga. Pengaruh negatif signifikan juga terlihat diantara hubungan Kepuasan Kerja terhadap Turnover Intentions. Kepuasan kerja adalah rasa senang dari karyawan dalam melaksanakan pekerjaannya. Work Engagement juga berpengaruh negatif signifikan terhadap Turnover Intentions. Work Engagement bisa diartikan apabila karyawan tersebut dapat mengidentifikasikan diri secara psikologis dengan pekerjaannya, dan menganggap kinerjanya penting untuk dirinya, selain untuk organisasi. Didasarkan pada hasil analisis maka terdapat pengaruh negatif signifikan antara Mentoring terhadap Turnover Intentions. Mentoring adalah bantuan secara tersembunyi "offline help" dari mentor ke mentee untuk transfer pengetahuan, pemikiran dalam kerja secara signifikan.

Didasarkan pada hasil analisis maka terdapat pengaruh negatif tidak signifikan antara Work - Life Balance yang dimoderasi Mentoring terhadap Turnover Intentions. Dimana kualitas hubungan antar karyawan perlu ditingkatkan lagi, agar pengaruhnya bisa signifikan. Pengaruh negatif tidak signifikan terlihat juga antara variabel Kepuasan Kerja yang dimoderasi Mentoring terhadap Turnover Intentions. Dimana kualitas hubungan antar karyawan perlu ditingkatkan lagi, agar pengaruhnya bisa signifikan. Work Engagement yang dimoderasi Mentoring pengaruh negatif tidak signifikan terhadap Turnover Intentions. Dimana kualitas hubungan antar karyawan perlu ditingkatkan lagi, agar pengaruhnya bisa signifikan.

Hasil penelitian ini menunjukkan Work - Life Balance berpengaruh negatif terhadap Turnover Intentions, mengandung implikasi bahwa keseimbangan tuntuntan pekerjaan dan kebutuhan berkumpul bersama keluarga sudah terpenuhi untuk karyawan, hal ini harus tetap terus dipertahankan dan ditingkatkan. Hasil penelitian ini juga menunjukkan Kepuasan Kerja yang berpengaruh negatif terhadap Turnover Intentions, mengandung implikasi bahwa perasaan senang dalam bekerja sudah dirasakan karyawan, keadaan tersebut harus terus ditingkatkan dan divariasi, agar karyawan tidak cepat bosan dengan keadaan yang monoton. Work Engagement berpengaruh negatif terhadap Turnover Intentions, mengandung implikasi bahwa keterikatan karyawan dengan perusahaan perlu terus dijaga dan ditingkatkan agar karyawan tetap merasa terikat dengan Hotel Dafam Semarang. Mentoring berpengaruh negatif terhadap Turnover Intentions, hal ini mengandung implikasi bahwa kegiatan mentoring dari mentor atau karyawan senior dengan mentee atau karyawan junior harus terus dipertahankan, begitu juga peralatan yang disediakan untuk melakukan pekerjaan harus 
terus di-upgrade agar karyawan semakin mantap dalam bekerja. Terkait kualitas hubungan antar karyawan juga perlu diperhatikan dan ditingkatkan, hal ini berpengaruh dalam menekan angka turnover.

\section{Keterbatasan Penelitian}

Penelitian ini mengungkapkan Turnover Intentions yang dipengaruhi oleh tiga faktor saja, yaitu Work - Life Balance, Kepuasan Kerja, dan Work Engagement, sedangkan faktor - faktor lain yang mempengaruhi Turnover Intentions sangat kompleks dan tidak diungkap dalam penelitian ini. Sehingga diharapkan untuk penelitian selanjutnya dapat mengungkapkan Turnover Intentions berdasarkan faktor faktor lain. Pengumpulan data dalam penelitian ini menggunakan kuesioner tertutup tanpa ada pertanyaan terbuka, sehingga membatasi karyawan Hotel Dafam Semarang dalam memberikan jawaban yang sesuai dengan keadaan karyawan Hotel Dafam Semarang.

\section{DAFTAR PUSTAKA}

Agoi, L. F. 2015. Effect of Work Engagement on Employee Turnover Intention in Public Sector, Kenya. International Journal of Economics, Commerce and Management.

Alniaçik, E., Alniaçik, Ü., Erat, S., \& Akçin, K. 2013. Does Person-organization Fit Moderate the Effects of Affective Commitment and Job Satisfaction on Turnover Intentions? Procedia - Social and Behavioral Sciences.

Alvesteffer, R. 2016. The Importance of Work Life Balance. IOSR Journal of Business and Management.

Andrea, B., Gabriella, H., \& Tímea, J. 2016. Y and Z Generations at Workplaces. Journal of Competitiveness.

Azeez, O. R., Jayeoba, F., \& Sdeoye, A. O. 2016. Job Satisfaction, Turnover Intention and Organizational. BVIMSR's Journal of Management Research.

Bejtkovský, J. 2016. The Current Generations : The Baby Boomers , X, Y and $Z$ in the Context of Human Capital Management of the 21st Century in Selected Corporations in the Czech Republic. The Cdentral European Journal of Social Sciences and Humanities.

Belias, D., \& Koustelios, A. 2014. Transformational Leadership and Job Satisfaction in the Banking Sector: A Review. International Review of Management and Marketing.

Bothma, C. F. C., \& Roodt, G. 2013. The validation of the turnover intention scale. SA Journal of Human Resource Management.

Çetin, A. T., Kız1l, C., \& Zengin, H. İ. 2013. Impact of Mentoring on Organizational Commitment and Job Satisfaction of Accounting-Finance Academicians Employed in Turkey. Emerging Markets Journal.

Chemirmir, M. J., Musebe, R., \& Nassiuma, B. K. 2018. The Role Of Work Life Balance On Employee Turnover In The Flower Industry In The North Rift Kenya. International Journal of Research in Social Sciences and Humanities.

Chun, J. U., Sosik, J. J., \& Yun, N. Y. 2012. A longitudinal study of mentor and protégé outcomes in formal mentoring relationships. Organizational Behavior.

Eby, L. T., Allen, T. D., Hoffman, B. J., Baranik, L. E., Sauer, J. B., Baldwin, S., Evans, S. C. (2013). An interdisciplinary meta-analysis of the potential antecedents, correlates, and consequences of protégé perceptions of mentoring. Psychological 
Bulletin.

Geldenhuys, M., Łaba, K., \& Venter, C. M. 2014. Meaningful work, work engagement and organisational commitment. SA Journal of Industrial Psychology.

Ghozali, I. 2015. Partial Least Square, Konsep, Teknik Dan Aplikasi Menggunakan Program SmartPLS 3.0 (2nd ed.). Semarang: Badan Penerbit Universitas Diponegoro.

Gupta, M., \& Shaheen, M. 2017. Impact of Work Engagement on Turnover Intention: Moderation by Psychological Capital in India. Verslas: Teorija Ir Praktika.

Hassan, M., Akram, A., \& Naz, S. 2012. The Relationship between Person Organization Fit, Person-Job-Fit and Turnover Intention in Banking Sector of Pakistan: The Mediating Role of Psychological Climate. International Journal of Human Resource Studies.

Jyoti, J., \& Sharma, P. 2015. Impact of Mentoring Functions on Career Development: Moderating Role of Mentoring Culture and Mentoring Structure. Global Business Review.

Liyanage, H. M., \& Gamage, P. 2017. Factors Influencing the Employee Engagement of the Generation Y Employees. Proceedings of APIIT Business \& Technology Conference.

Mahdi, A. F., Zin, M. Z. M., Nor, M. R. M., Sakat, A. A., \& Naim, A. S. A. 2016. The Relationship Between Job Satisfaction and Turnover Intention Faculty of Business Management. Department of Al Quran and Al Sunnah Studies ,. American Journal of Applied Sciences.

Naim, M. F., \& Lenka, U. 2017. How does mentoring contribute to Gen Y employees' intention to stay? An indian perspective. Europe's Journal of Psychology.

Nindyati, A. D. 2017. Pemaknaan Loyalitas Karyawan Pada Generasi X Dan Generasi Y (Studi Pada Karyawan Di Indonesia). Journal of Psychological Science and Profesion.

Nkomo, M. W., \& Thwala, W. D. 2018. Advances in Human Factors in Training, Education, and Learning Sciences. Springer International Publishing.

Olawale, R., \& Olarewaju, A. 2016. Job Satisfaction, Turnover Intention and Organizational. BVIMRS's Journal of Management Research.

Oosthuizen, R., Coetzee, M., \& Munro, Z. 2016. Work-life balance, job satisfaction and turnover intention amongst information technology employees. Southern African Business Review.

Queiri, A., Wan Yusoff, W. F., \& Dwaikat, N. 2015. Explaining generation-Y employees' turnover in Malaysian context. Asian Social Science.

Siagian, S. P. 2012. Teori Motivasi dan Aplikasinya (3rd ed.). Jakarta: PT Rineka Cipta.

Suifan, T. S., Abdallah, A. B., \& Diab, H. 2016. The influence of work life balance on turnover intention in private hospitals: The mediating role of work life conflict. European Journal of Business and Management.

Sutrisno, E. 2017. Manajemen Sumber Daya Manusia (9th ed.). Jakarta: Kencana.

Takawira, N., Coetzee, M., \& Schreuder, D. 2014. Job embeddedness, work engagement and turnover intention of staff in a higher education institution: An exploratory study. SA Journal of Human Resource Management.

Weyland, A. 2011. Engagement and talent management of Gen Y. Industrial and Commercial Training.

Woo, H. R. 2017. Exploratory study examining the joint impacts of mentoring and managerial coaching on organizational commitment. Sustainability (Switzerland). 
Zhang, W., Meng, H., Yang, S., \& Liu, D. 2018. The influence of professional identity, job satisfaction, and work engagement on turnover intention among township health inspectors in China. International Journal of Environmental Research and Public Health.

Zhao, L., \& Zhao, J. 2017. A Framework of Research and Practice: Relationship between Work Engagement, Affective Commitment, and Turnover Intentions. Open Journal of Social Sciences. 